\title{
SYNTHESIS OF $\gamma$ - ALUMINA BY SOLUTION COMBUSTION METHOD USING MIXED FUEL APPROACH (UREA+GLYCINE FUEL)
}

\author{
Baburao N. Sherikar ${ }^{1}$, Arun M .Umarji ${ }^{2}$ \\ ${ }^{1}$ Materials Research Centre Indian Institute of Science Bangalore India \\ ${ }^{2}$ Department of Ceramic and Cement Technology P.D.A.College of Engineering Gulbarga India \\ shantbabu@gmail.com
}

\begin{abstract}
Nano crystalline $\gamma$-Alumina powders were synthesized by Solution Combustion reaction between aluminium nitrate as oxidizer and a mixture of urea and glycine fuel as reducer. In this fuel mixture, urea was taken as stoichiometric fuel and glycine was added as excess fuel to alter the exothermicity of redox reaction between aluminium nitrate and urea. The ratio of urea to glycine had been optimized to obtain single phase gamma alumina. A Multi channel thermocouple setup was used to measure the flame temperatures to study the nature of combustion of various fuel mixtures. The variation of adiabatic flame temperature was calculated theoretically for different urea/glycine mixture ratios according to thermodynamic concept and correlated with the observed flame temperatures. These powders were characterized by XRD, SEM, showing that the powders were composed of polycrystalline oxides with crystallite size of $81 \mathrm{~nm}$ for alpha alumina, $5 \mathrm{~nm}$ for gamma alumina and having highly porous microstructure. An interpretation based on maximum combustion temperature and the amount of gases produced during reaction for various urea to glycine ratio composition had been proposed for the nature of combustion and its correlation with the characteristics of as synthesized powder.
\end{abstract}

Keywords: Nano crystalline materials, Gamma Alumina; Adiabatic flame temperature; Solution combustion route; Urea+glycine mixture, Multi channel thermocouple setup, X-ray diffraction, Mixed fuel approach,

\section{INTRODUCTION}

Nanocrystalline $(\gamma)$ alumina is a polytype of alumina that find extensive applications as a catalyst and catalytic supports due to its high surface area and porosity. These properties result primarily from the nano-scale character of the alumina. Many attempts have been made in literature to address the synthesis of gamma alumina by using kaolin [1,2], boehmite sol [3], saccharide molecule template [4] hydrothermal method [5,6], precipitation method $[7,8,9]$, sol-gel process $[10,11]$, resin synthesis method [12] , solvothermal route [13], reductionmagnetic separation method [14]. But these methods are time consuming, expensive and complex. Solution Combustion Synthesis (SCS) provides simple, low cost fast process, with energy and time saving to produce pure nano crystalline ceramic powders [15]. $(\gamma)$ alumina is synthesized by oxalyl dihydrazide $(\mathrm{ODH})$ fuel which is hydrazine hydrate derivative and a carcinogenic. Except urea and glycine, most of the other fuels $(\mathrm{ODH}$, carbohydrazide etc) used in the SCS are hydrazine derivatives. J.C .Toniolo et al [16] obtained amorphous product during aluminum nitrate glycine combustion with varying the oxidizer to fuel ratio. Only on heating as prepared powder to $1073 \mathrm{~K} \gamma$ alumina phase is formed.
Usage of mixed fuel approach to synthesis various ceramics have been done earlier $[17,18,19]$. However, till now there is no report of synthesis of gamma alumina by Solution Combustion Synthesis using mixed fuel approach explaining the thermodynamic concept. In this work effect of mixed fuel approach using urea and glycine fuels on aluminiumnitrate fuel combustion was investigated. Theoretical temperature and enthalpy of reaction were calculated on thermodynamic concept and correlated with the measured temperature. Urea to glycine ratio was optimized to achieve pure gamma alumina phase in as prepared state.

\section{EXPERIMENTAL PROCEDURE}

The reactants analytical grade aluminium nitrate nonahydrate $\mathrm{Al}\left(\mathrm{NO}_{3}\right)_{3} \cdot 9 \mathrm{H}_{2} \mathrm{O}$ was used as oxidizer. The urea $\left[\mathrm{CO}\left(\mathrm{NH}_{2}\right)_{2}\right]$ and glycine $\left(\mathrm{C}_{2} \mathrm{H}_{5} \mathrm{NO}_{2}\right)$ were used as fuel. The molar ratios/amount of reactants are shown in Table1. The fuel mixture composition is designed such that amount of fuel urea is taken according to stoichiometric condition and kept constant for all composition and glycine fuel was added as excess fuel to urea with wt equivalent to $0,10,20,30,40 \mathrm{wt} \%$ of urea, means for $3 \mathrm{gm}$ of urea glycine was added as 0.0, 0.3, 0.6, 0.9, $1.2 \mathrm{~g}$ respectively. Totally five sample compositions were made with notation, U00G, U10G, U20G, U30G, and U40G. 
The Above compositions were dissolved in minimum amount of deionized water to make clear solutions. These solutions were then kept in furnace preheated to $773 \mathrm{~K}$. First thermal dehydration occured at $\sim 373 \mathrm{~K}$, at $\sim 473 \mathrm{~K}$ the viscous liquids swelled and auto ignited, with the rapid evolution of large volume of gases. Here combustion reaction takes place between decomposition products of oxidizer and fuel leading to exothermic reaction giving huge amount of energy in terms of heat and the local temperature generated may be nearly $1773 \mathrm{~K}$ which helps in forming the ceramic oxide. The ash obtained after releasing of gases was the desired ceramic product. Whole reaction completes within a span of six to seven minutes. The obtained product was highly porous due to huge number of gases released during process .All combustion calculations are mentioned in our earlier paper [20]. The powder color varied with number of moles of glycine $(\Psi)$. At $\Psi=0$, it was white and changes to gray at $\Psi=1.6$. The color change was due to residual carbon of incomplete combustion. Under the equilibrium conditions the standard reaction equation of systems can be represented for all nitrate- Urea/glycine ratio combustion

$$
\begin{aligned}
2 \mathrm{Al}\left(\mathrm{NO}_{3}\right)_{3} \cdot 9 \mathrm{H}_{2} \mathrm{O}+5 \mathrm{NH}_{2} \mathrm{CONH}_{2}+\Psi \mathrm{NH}_{2} \mathrm{CH}_{2} \mathrm{COOH}+2.25 \Psi \mathrm{O}_{2} \rightarrow \\
\mathrm{Al}_{2} \mathrm{O}_{3}+(8+0.5 \Psi) \mathrm{N}_{2}+(5+2 \Psi) \mathrm{CO}_{2}+(28+2.5 \Psi) \mathrm{H}_{2} \mathrm{O} \ldots(1)
\end{aligned}
$$

\section{THERMODYNAMIC MODELLING}

As Solution Combustion Synthesis was fast and completed in few seconds, it was be assumed as adiabatic. Temperature generated due to the exothermic reaction was adiabatic temperature. Using the thermodynamic data for the various reactants and products listed in Table II, the enthalpy of combustion and the theoretical adiabatic flame temperatures as a function of urea/glycine ratio were approximately calculated by the following equations using Mathematica software for comparing exothermicity of combustion

$$
\Delta \mathrm{H}^{\mathrm{o}}=\left(\sum \mathrm{n} \Delta \mathrm{H}^{\mathrm{o}}\right){ }_{\text {products }}-\left(\sum \mathrm{n} \Delta \mathrm{H}^{\mathrm{o}}\right)_{\text {reactants }}
$$

$\Delta \mathrm{H}^{\mathrm{o}}=\int_{298}^{\mathrm{T} \text { ad }}\left(\mathrm{nC}_{\mathrm{p}}\right)_{\text {products }} \mathrm{dT}$

\begin{tabular}{|c|c|c|c|c|c|c|c|c|c|c|c|}
\hline $\begin{array}{l}\text { Sl. } \\
\text { No }\end{array}$ & $\begin{array}{l}\text { Sampl } \\
\text { e code }\end{array}$ & $\begin{array}{c}\mathrm{Al}(\mathrm{N} \\
\mathrm{O})_{3} \\
(\mathrm{~g})\end{array}$ & $\begin{array}{l}\text { Urea } \\
(\mathrm{g})\end{array}$ & $\begin{array}{l}\text { Glyci } \\
\text { ne }(g)\end{array}$ & $\Psi$ & $\begin{array}{l}\mathrm{T}_{\mathrm{ad}} \\
(\mathrm{K})\end{array}$ & $\begin{array}{l}\text { Measu } \\
\text { red } \\
\text { Temp } \\
(\mathrm{K})\end{array}$ & $\begin{array}{c}\Delta \mathrm{H}^{\mathrm{O}} \\
(\mathrm{kcal} / \\
\mathrm{mol})\end{array}$ & Color & $\begin{array}{c}\text { Obtained } \\
\text { Powder / } \\
1 \mathrm{gm} \\
\text { desired }\end{array}$ & $\begin{array}{l}\text { Nature of } \\
\text { combustion }\end{array}$ \\
\hline 1 & U00G & 7.5 & 3 & 0.00 & $\begin{array}{l}0 . \\
0\end{array}$ & 1390 & 1263 & -375.21 & White & 0.940 & Flaming \\
\hline 2 & U10G & 7.5 & 3 & 0.30 & $\begin{array}{c}0 . \\
4\end{array}$ & 1569 & 1143 & -457.76 & White & 0.904 & Flame + smoldering \\
\hline 3 & U20G & 7.5 & 3 & 0.60 & $\begin{array}{c}0 . \\
8\end{array}$ & 1733 & 1121 & -540.31 & grey & 1.036 & smoldering \\
\hline 4 & U30G & 7.5 & 3 & 0.90 & $\begin{array}{l}1 . \\
2\end{array}$ & 1882 & 1100 & -622.85 & grey & 1.096 & smoldering \\
\hline 5 & $\mathrm{U} 40 \mathrm{G}$ & 7.5 & 3 & 1.20 & $\begin{array}{l}1 . \\
6\end{array}$ & 2020 & 1081 & -705.40 & grey & 1.130 & smoldering \\
\hline
\end{tabular}

Table.1 Composition of reactants, Tad, Measured Temperature, Enthalpy of combustion, Nature of combustion 
Here $\Delta \mathrm{H}^{\circ}$ is the enthalpy of combustion reaction, $\mathrm{Cp}$ is the heat capacity of products at constant pressure and $\mathrm{T}_{\mathrm{ad}}$ is the adiabatic flame temperature in Kelvin. Number of moles of gases evolved per mole of product also calculated for all reactions.

\begin{tabular}{|l|l|l|}
\hline \multicolumn{3}{|c|}{ Table .2. } \\
\hline Compound & $H \mathrm{f}(\mathrm{kcal} / \mathrm{mol})$ & $\mathrm{Cp} \mathrm{cal} /(\mathrm{mol} \mathrm{K}) \mathrm{a}$ \\
\hline $\mathrm{Al}\left(\mathrm{NO}_{3}\right)_{3} \cdot 9 \mathrm{H}_{2} \mathrm{O}(\mathrm{c})$ & --857.59 & \\
\hline $\mathrm{NH}_{2} \mathrm{CONH}_{2}$ & -79.71 & \\
\hline $\mathrm{NH}_{2} \mathrm{CH}_{2} \mathrm{COOH}(\mathrm{c})$ & $-126.22)$ & \\
\hline $\mathrm{Al}_{2} \mathrm{O}_{3}(\mathrm{c})$ & --400.4 & $22.08+0.0089 \mathrm{~T}$ \\
\hline $\mathrm{CO}_{2}(\mathrm{~g})$ & -94.051 & $10.34+0.0027 \mathrm{~T}$ \\
\hline $\mathrm{N}_{2}(\mathrm{~g})$ & 0 & $6.5+0.0010 \mathrm{~T}$ \\
\hline $\mathrm{H}_{2} \mathrm{O}(\mathrm{g})$ & -57.796 & $8.22+0.00015 \mathrm{~T}$ \\
\hline $\mathrm{O}_{2}(\mathrm{~g})$ & 0 & $8.27+0.000258 \mathrm{~T}$ \\
\hline
\end{tabular}

\section{ENTHALPY OF COMBUSTION AND}

\section{ADIABATIC FLAME TEMPERATURE $\left(\mathbf{T}_{\mathrm{AD}}\right)$}

The $\Delta \mathrm{H}^{\circ}$ and the $\mathrm{T}_{\mathrm{ad}}$ as function of urea/glycine ratio are shown in Table.1. It was seen that $\Delta \mathrm{H}^{\mathrm{o}}, \mathrm{T}_{\mathrm{ad}}$ and number of moles of gases evolved were directly proportional to the amount of glycine, varying linearly in ascending manner. The variation can be expressed in linear equation as $\Delta \mathrm{H}^{0}=375-206$ $\Psi, \mathrm{T}_{\mathrm{ad}}=393 \Psi+1404 \mathrm{~K}$ and number of moles of gases evolved $=5 \Psi+31$. The reaction between urea and aluminum nitrate at stoichiometric ratio for $\Psi=0$ mole of glycine had lowest exothermicity and adiabatic flame temperature of $1390 \mathrm{~K}$. Adiabatic temperatures for $\Psi=0.4,0.8,1.2,1.6$ are 1569, 1733, 1880, 2020K, respectively. But measured flame temperatures were very low and inversely proportional to the number of moles of glycine. Low temperature might be due to heat loss, heat capacity \& thickness of thermocouple. But here glycine plays major role instead of increasing it decreased the combustion temperature due to its complexing ability, zwitter ionic nature which might have formed the temporary complex and might be decomposed later without forming the hypergolic mixture of gases $(\mathrm{HCNO}+\mathrm{NOX}+\mathrm{NH} 3$ which were necessary to form to give exothermic reaction releasing huge energy) and also the high number of carbon atoms present in glycine decrease the flame temperature due to zero value of their enthalpy of formation. In spite of high reaction enthalpy and $\mathrm{T}_{\mathrm{ad}}$ observed for all cases the crystalline phase had not formed for $\Psi=1.2,1.6$.This might be due to the strong coordination compound formation in between the fuel glycine and nitrate which prevented the release of the aluminium cations to form compound.

\section{PHASE FORMATION AND MORPHOLOGY}

$\mathrm{X}$-ray diffraction was carried on the combustion-synthesized powders for phase identification scanned at a rate of $1 \% \mathrm{~min}$, using $\mathrm{Cu}-\mathrm{K}_{\text {_ }}$ radiation on a Brukers D8 diffractometer, and the crystallite size estimation was done using Scherrer formula .Silicon was used as an external standard for correction due to instrumental broadening. Microstructure studies on the powders were carried out by using QUANTA 200 ESEM FEI. Scanning electron microscope

Fig 1 shows XRD pattern of the as-synthesized powders of different urea to glycine ratio. The formation of phase pure crystalline $\alpha$-alumina is confirmed for the case $\Psi=0$ as the amount of glycine content increases the phase formation also changes adding 0.4 moles of glycine the phase changes from pure alpha alumina to mixture of alpha and gamma alumina. Finally it converts to completely to gamma alumina at addition of 0.8 moles of glycine to the composition. U20G composition shows the pure gamma alumina formation which is confirmed by comparing the peaks with JCPDS Card No 29-0063, and alpha alumina peaks were compared to the peaks of standard JCPDS Card No 46-1212. Further increasing the glycine content the phase changes to amorphous at 1.6 moles of glycine .The change in phases from high temperature alpha corundum phase to low temperature gamma phase and amorphous phase even at high theoretical temperature and enthalpy is due to incomplete combustion taking place due to high number of carbon atoms present in glycine which leads to the formation of carbon residue due to zero enthalpy of formation and also glycine being complexing agent and zwitter ionic nature leads to formation of temporary legand complex formation which will have high decomposition 
temperature and prevent the formation of hypergolic gases. It can be seen that crystallite size is highest $\Psi=0$ at stoichiometric $(81 \mathrm{~nm})$ due to sintering of fine particles from high local temperature, decreases as one moves to fuel rich composition $\Psi=0.4,0.8,1.2,1.6$ due to low local temperature preventing the sintering of particles . Fig.2(a) illustrates TEM micrographs of SCS powder of stoichiometric alumina showing an aggregate of crystallites of dimension $300 \mathrm{~nm}$ with average crystallite size of $80-90 \mathrm{~nm}$. Fig 2 (b), shows the SEM micrographs of alumina powder of $\Psi=0$ of $400 \mu \mathrm{m}$ and 300 $\mu \mathrm{m}$, with porous structures respectively due to high and less froth/gel formation in reactions. Fig. 2(c) shows the average crystallite size of $\sim 5 \mathrm{~nm}$ of $\gamma$-Alumina.
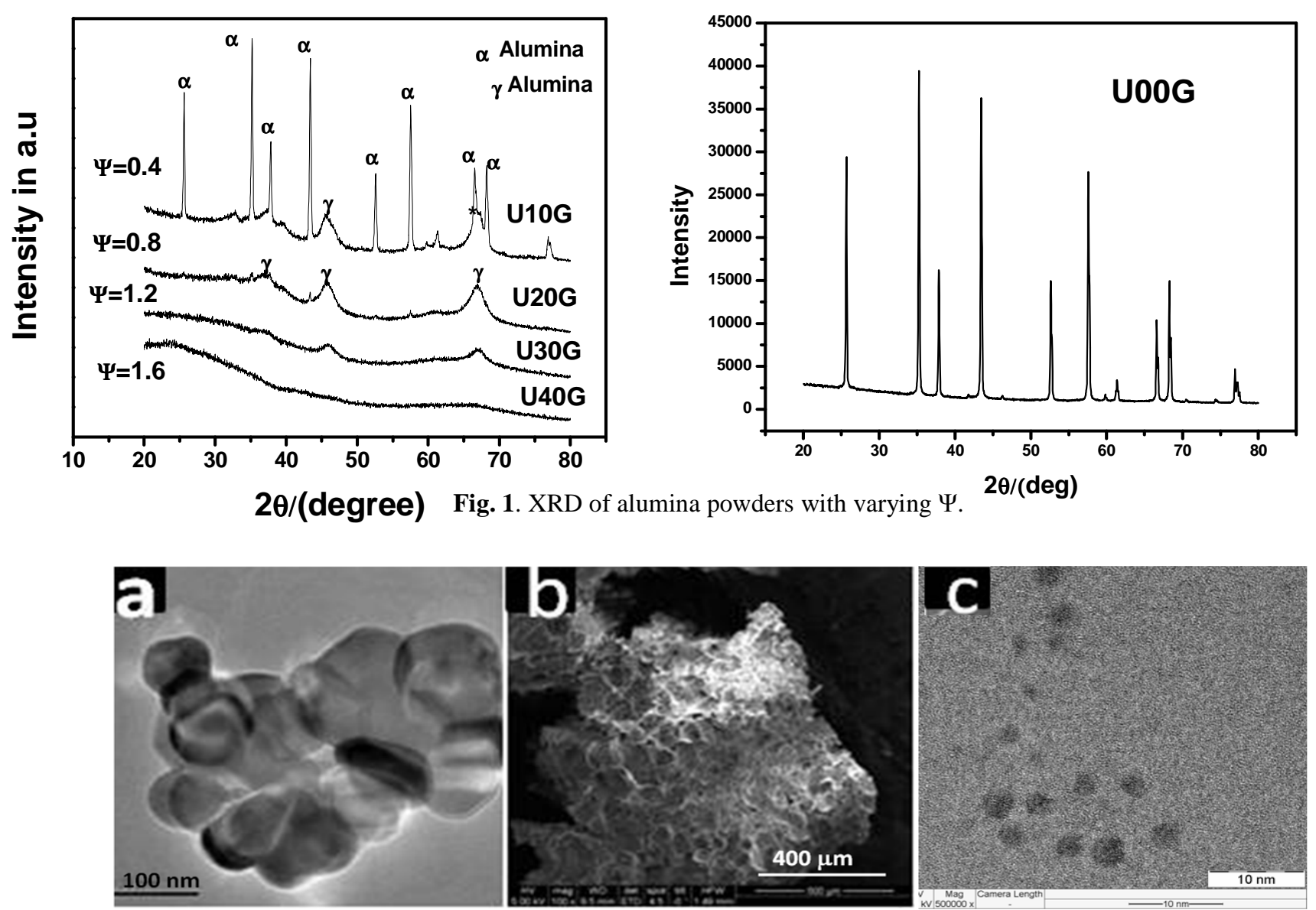

Fig2 (a) TEM of U00G $\quad$ (b) SEM of U00G (c) TEM of U20G

\section{CONCLUSIONS}

A mixture-of-fuels approach has been employed to rapidly synthesize single phase polycrystalline powders of $\gamma$-Alumina using a mixture of urea and glycine as fuel in a solutioncombustion method. The ratio of urea to glycine has been optimized to obtain single phase gamma alumina. For U20G ( $\Psi=0.8$ ) composition pure gamma alumina phase obtained. The powder was nanocrystalline in nature with average crystallite size of $\sim 5 \mathrm{~nm}$ as confirmed by XRD and highly porous as confirmed by SEM.
Theoretical adiabatic flame temperatures were calculated according to the thermodynamic concept and compared with the measured data. It was found that the theoretical adiabatic temperature increased with increasing the value of glycine to a maximum of $2020 \mathrm{~K}$ (at $\Psi=1.6$ ) but measured temperature for the same was $1081 \mathrm{~K}$. This huge difference in temperature may be due to more moles of gases formed during combustion take away the heat generated and also due to incomplete combustion occurred due to more no of carbon atoms present in glycine. Glycine fuel reduces the exothermicity of combustion reaction and acting as both complexing agent and fuel. 


\section{REFERENCES}

[1]. Huaming Yang, Mingzhu Liu, Jing Ouyang, Novel synthesis and characterization of nanosized $\gamma-\mathrm{Al}_{2} \mathrm{O}_{3}$ from kaolin, Applied Clay Science 47 (2010) 438-443

[2]. Seyed Ali Hosseini, Aligholi Niaei, Dariush Salari ,Production of $\gamma-\mathrm{Al}_{2} \mathrm{O}_{3}$ from Kaolin ,Open Journal of Physical Chemistry, 2011, 1, 23-27

[3]. Qian Liu, Aiqin Wang, Xuehai Wang, Peng Gao, Xiaodong Wang, Tao Zhang, Synthesis ,characterization and catalytic applications of mesoporous gamma alumina from boehmite sol, Microporous and Mesoporous Materials, Volume 111, Issues 1-3, 15 April 2008, Pages 323-333

[4]. Benjing $\mathrm{Xu}$, Jun Long, Huiping Tian, Yuxia Zhu, Xin Sun, Synthesis and characterization of mesoporous gammaalumina templated by saccharide Molecules, Catalysis Today 147S (2009) S46-S50

[5]. Hyun Chul Lee, Hae Jin Kim, Chang Houn Rhee, Synthesis of nanostructured $\gamma$-alumina with a cationic surfactant and controlled amounts of water Microporous and Mesoporous Materials 79 (2005) 61-68

[6]. Ye Liu, Ding Ma, Xiuwen Han, Xinhe Bao, Wiebke Frandsen, Di Wang, Dangsheng Su, Hydrothermal synthesis of microscale boehmite and gamma nanoleaves alumina, Materials Letters,

Volume 62, Issue 8-9, 31, March 2008, pages 1297-1301

[7]. K.M. Parida, A.C.Pradhan, J.Das, Nruparaj Sahu Synthesis and characterization of nano-sized porous gammaalumina by control precipitation method Materials Chemistry and Physics Vol 113, Issue 1, 2009, Pages 244-248

[8]. H.S.Potdar, Ki-Won Jun, JongWook Bae, Seung-Moon Kim ,Yun-JoLee, Synthesis of nano-sized porous $\gamma$-alumina powder via a precipitation/digestion route, Applied Catalyst A; General Volume 321,Issue2,11 April 2007,Pages 109-116

[9]. Shaoyan Wang,Xiaoan Li, Shaofeng Wang, Yang $\mathrm{Li}$,Yuchun Zhai Synthesis of $\gamma$-alumina via precipitation in ethanol ,Materials Letters volume 62,Issue20,31,July 2008, Pages 3552-3554

[10]. Genoveva Buelna, Y.S. Lin,Sol-gel-derived mesoporous c-alumina granules, Microporous and Mesoporous Materials 30 (1999) 359-369

[11].Abbas Khaleel, Shamsa Al-Mansouri Meso-macroporous $\gamma$ alumina by template-free sol-gel synthesis; The effect of the solvent and acid catalyst on the microstructure and texture properties

Colloids and Surfaces A; Physicochemical and Engineering Aspects, volume 369,Issues 1-3,20 october 2010 pages 272280

[12]. D.M. Ibrahima, Y.M. Abu-Ayanab, Preparation of nano alumina via resin synthesis, Materials Chemistry and Physics 113 (2009) 579-586

[13]. Ming-Guo Ma, Jie-Fang Zhu , A facile solvothermal route to synthesis of $\gamma$-alumina with bundle-like and flowerlike morphologies, Materials Letters 63 (2009) 881-883

[14]. Pengcheng Liu, Junting Feng, Xiangmei Zhang, Yanjun Lin, David G. Evans, Dianqing Li,Preparation of high purity spherical g-alumina using a reduction-magnetic separation process

Journal of Physics and Chemistry of Solids 69 (2008) 799-804

[15]. K C, Patil ,M.S Hegde,T. Rattan, S.T.Aruna Chemistry of nanocrystalline oxide materials; combustion synthesis, properties Sinapore;World Scientific;2008.

[16]. J.C. Toniolo, M.D. Lima, Takimi, A.S., and Bergmann, C.P Synthesis of alumina powders by the glycine-nitrate combustion process Materials. Research. Buletein.,2005, vol. 40, pp. 561-571.

[17]. S.T. Arunaa, N.S. Kinib, Satish Shetty, K.S. Rajama Synthesis of nanocrystalline $\mathrm{CeAlO}_{3}$ by solution-combustion route Materials Chemistry and Physics 119 (2010) 485-489

[18]. S. Banerjee, P. Sujatha Devi Sinter-active nanocrystalline $\mathrm{CeO}_{2}$ powder prepared by a mixed fuel process: Effect of fuel on particle agglomeration Journal of Nanoparticle Research (2007) 9:1097-1107

[19]. S.K. Ghosh, A. Prakash, S. Datta, S.K Roy, D.Basu Effect of fuel characteristics on synthesis of calcium hydroxyapatite by solution combustion route Bulletin of Materials Science, Vol. 33, 2010, pp. 7-16

[20]. Baburao Sherikar N,Umarji A M, Effect of adiabatic flame temperature on nano alumina powders during solution combustion process Transactions of Indian Ceramic Society. 70(3) 167-172(2011)

[21]. R.H. Perry, C.H. Chilton, Chemical Engineering Handbook, 7th edn. (McGraw-Hill, New York, 1997).

[22]. D. R.Lide, CRC Handbook of Chemistry and Physics 72nd edn. (CRC Press ,Boston 1991-1992). 